\title{
Administración pública y los principios del derecho administrativo en Perú
}

\author{
PIERO ROJAS ${ }^{1}$
}

\section{RESUMEN}

El proyecto de la Ley de Bases de la Administración Pública es el primer instrumento jurídico que desarrolla los estándares fundamentales de la organización y funcionamiento de la administración pública en Perú. En tal sentido, objeto del presente trabajo de investigación es reflexionar y hacer comentarios críticos sobre el tratamiento jurídico que le ha otorgado el proyecto de ley al concepto de administración pública y a los principios que rigen su funcionamiento.

Palabras clave: administración pública, entidad pública, principios del derecho administrativo, proyecto de la Ley de Bases de la Administración Pública, derecho administrativo.

\section{Public Administration and the Principles of Administrative Law in Peru}

\section{ABSTRACT}

The Draft Law on Peru's Public Administration Framework is the first legal instrument that develops the fundamental standards of the organization and functioning of public administration. This piece seeks to reflect and provide

1 Miembro del área de Derecho Administrativo de Linares Consultores, Lima, Perú. Abogado de la Universidad Peruana de Ciencias Aplicadas (UPC), Lima, Perú. Adjunto de cátedra de los cursos de Derecho Administrativo en la UPC, PUCP y en la Universidad ESAN, Lima, Perú. Correo-e: pierorv28@gmail.com Fecha de recepción: 2 de febrero de 2015. Fecha de modificación: 23 de marzo de 2015. Fecha de aceptación: 3 de abril de 2015. Para citar el artículo: ROJAS, P. (2015). Administración pública y los principios del derecho administrativo en Perú. Revista Digital de Derecho Administrativo n. ${ }^{\circ} 13$, Universidad Externado de Colombia, pp. 193-209. DOI: 10.18601/21452946.n13.10 
critical commentary on how this bill deals legally with the concept of public administration and its main principles governing its operation.

Keywords: Public Administration, Public Entity, Principles of Administrative Law, Draft Law on Public Administration Framework, Administrative Law.

\section{INTRODUCCIÓN}

La administración pública es un instrumento para alcanzar un desarrollo social y económico sostenido, pero también debe entenderse como un camino para lograr que los avances que se generan en el Estado puedan llegar también a las masas poblacionales y que la distribución favorezca también a los que más lo necesitan y no solo a los que más tienen. Sin embargo, dicho cometido no puede ser cumplido sin la estructuración de bases sólidas que permitan determinar cuándo nos encontramos frente la administración pública. En un intento de generar uniformidad, predictibilidad y certeza con relación a los organismos y entidades que integran la estructura de la administración pública, el Ministerio de Justicia constituyó un grupo de trabajo con la función de elaborar un "Proyecto de la Ley de Bases de la Administración Pública" que permita establecer reglas claras de organización de las entidades de la administración pública, como sujetos de derecho administrativo. En tal sentido, luego de un largo periodo, mediante Resolución n. ${ }^{\circ}$ 0223-2014-Jus, se publicó en el Diario Oficial "El Peruano" el "Proyecto de la Ley de Bases de la Administración Pública", con el objetivo de difundir las principales conclusiones del Grupo de trabajo del Ministerio de Justicia y permitir a los ciudadanos presentar sus opiniones sobre dicho proyecto.

La presente investigación tiene el fin de analizar los puntos importantes de este proyecto de ley, a partir de aquello que la doctrina identifica bajo el término de "administración pública" y los principios que rigen su funcionamiento. Se trata de estudiar la organización administrativa como función, esto es, como actividad tendiente a definir la estructura de la administración pública en Perú. Determinar el alcance que del término "administración pública" a partir del texto del proyecto de reforma legislativa supone comenzar por establecer el sentido que a esta expresión le otorgan la doctrina y la legislación positiva, antes de examinar su conformidad con los principios y fundamentos en materia de organización administrativa presentes en la legislación peruana.

\section{LA NOCIÓN DE ADMINISTRACIÓN PÚBLICA EN DERECHO ADMINISTRATIVO PERUANO}

Establecer aquello que en derecho peruano se conoce bajo la expresión "administración pública" implica comenzar por identificar el criterio que se em- 
pleará para su definición, antes de establecer el sentido que la noción tiene en el ordenamiento jurídico nacional.

\section{LA DÍFICIL TAREA DE DETERMINACIÓN DEL CONTENIDO DE LA "ADMINISTRACIÓN PÚBLICA"}

La administración pública, tal como hoy la conocemos, nace con una clara dependencia del principio de separación de poderes y, como consecuencia, de la diferenciación de funciones entre esos mismos poderes ${ }^{2}$. Aunque sea posible identificar en el Antiguo Régimen algunas de las funciones que actualmente ejerce la administración, esas funciones eran realizadas bajo un régimen jurídico diferente. En términos específicos, la distinción de los tradicionales poderes públicos, y la atribución a cada uno de ellos de una función específica: legislar, juzgar o administrar, es el presupuesto político de existencia de un derecho administrativo y de reglas aplicables a la organización administrativa. Ahora bien, en sus inicios como disciplina autónoma, y hasta el último tercio del siglo XIX, la organización en sus dimensiones subjetiva -como el conjunto de orgános que integran la administración pública-y funcional-como función de determinar cuál es la estructura de la administración- fue objeto de pocos desarrollos ${ }^{3}$. En el contexto francés y de otros países que adoptaron un modelo centralista de organización, la administración pública tiende en esta época a identificarse con el poder ejecutivo. La identidad entre el sujeto y la función durante este período, permite conceptualizar con nitidez tanto a la administración pública como a la función administrativa. La primera se identifica con el poder ejecutivo, la segunda consiste en la actividad desarrollada por ese sujeto. De acuerdo con este concepto subjetivo, solo al poder ejecutivo, esto es, a la administración pública, se le aplica el peculiar régimen jurídico que es el derecho administrativo (GARCÍA DE ENTERRÍA y RAMÓN FERNÁNDEZ, 2002, p. 28).

A partir del último tercio del siglo XIX la doctrina comienza a cuestionarse acerca de esa correspondencia entre poder ejecutivo y función administrativa. A partir de ese momento se intenta determinar cuál es el contenido de la función que permite caracterizar a la administración pública. En otras palabras, se produce una ruptura entre el sujeto y la función. Por consiguiente, habrá administración pública donde se realice la actividad, con independencia de

2 Para mayor información sobre el principio de separación o división de poderes, cfr. GARCía de EnTerRía, E. y Ramón Fernández T. (2002). Curso de Derecho Administrativo, t. I. Madrid: Civitas; Santofimio Gamboa, J. (2007). Tratado de Derecho Administrativo, t. I. Bogotá: Universidad Externado de Colombia; cfr., además, sentencia del Tribunal Constitucional peruano recaída en el expediente n. ${ }^{\circ} 01761$-2008-AA de 7 de abril de 2010.

3 Forsthoff, ERnST (1958). Tratado de Derecho Administrativo. Madrid: Instituto de Estudios Políticos y Constitucionales, pp. 546 y 547. 
quién sea el sujeto que la realice. El derecho administrativo será así el régimen aplicable a esa función (ABRUÑa y BACA, 2014, p. 5).

Lo anterior permite observar que desde sus inicios el concepto de administración pública no ha sido uniforme. Esto lleva a cuestionarnos, en primer lugar, sobre la pertinencia misma del concepto. Para el caso peruano, encontramos que la respuesta no puede ser sino afirmativa, ya que en función del sentido dado a la expresión "administración pública" es que se puede aplicar un régimen jurídico determinado a ciertos sujetos de derecho. No obstante, la doctrina moderna, en su intento de determinar quién y bajo qué cricunstancias puede ser cobijado bajo la noción de administración pública, ha pretendido identificar diferentes criterios, como son el subjetivo, el objetvio y el mixto (GARCía DE ENTERRía y RAMÓN FERNÁNDEZ, 2002, p. 29).

Parte de la doctrina actual considera que no es posible categorizar a la administración pública por medio de una función típica, lo que la ha llevado a adoptar un criterio subjetivo. Como prueba de esto, GARRIDO FALLA (1994, p. 39) sostiene que el criterio subjetivo tuvo una primera versión extrema, que identificaba a la función administrativa con toda la actividad que desarrollaba la rama ejecutiva del poder público. Sin embargo, es posible indicar que, con el pasar del tiempo, en derecho peruano este criterio no solo avoca a esta rama del poder, sino que se ha extendido a otros órganos. En este sentido, IVANEGRA (2005, p. 31), citando a MERKL, indica que la "administración pública" son las funciones del conjunto de organismos y entidades que se rigen por relaciones de dependencia y que se traducen en el derecho que tiene el órgano superior de dar instrucciones y en el deber de obedecerlas del órgano inferior. Se trata de una doctrina enfocada en una relación "órgano-función". En esa misma línea, y de manera complementaria, se afirma que, en atención al criterio subjetivo, las características que la administración pública debe ostentar para ser reconocida como tal son las siguientes: la existencia de una organización del poder público y el ejercicio por esta de una función estatal (ABRUÑA, 2011, p. 17). En definitiva, lo que determina a la administración pública como objeto de derecho administrativo no es la simple función calificada como administrativa, sino la existencia de órganos de esta naturaleza que conforman una estructura administrativa, esto es, un cuerpo de sujetos de derecho público y organismos administrativos. Bajo este enfoque, el derecho administrativo no se define a partir de un contenido material o sustancial, sino mediante la idea de un aparato estatal (SANTOFINIMIO, 2007, p. 50).

La aparición de los procesos de descentralización y la aparición de entes territoriales y sujetos particulares que ejercen función administrativa lleva a que en la tradición peruana se quiebre la identificación entre orgáno y función. La insuficiencia del criterio subjetivo lleva a que la doctrina comience a acuñar concepcines funcionales. De esta forma, la administración ya no puede identificarse por un órgano, de tal suerte que donde se encuentre la función se encontrará la administración pública, y ello con independencia del sujeto 
que la ejerza (ABRUÑA, 2011, p. 17). Con la aparición de un criterio objetivo se establece además en la doctrina que la actividad debe ser calificada según su contenido como función administrativa, sin tener en cuenta el órgano que las ejerce. De ahí que se reconozca que puede ser ejercida incluso por otras ramas del poder público (IVANEGRA, 2005, p. 32). A diferencia del criterio subjetivo, lo determinante es el reconocimiento como administración pública de la actividad permanente, directa y concreta a ejercer por el Estado y cuya finalidad sea la satisfacción del interés general. El criterio objetivo no se encuentra sin embargo exento de críticas, en esepcial por la ausencia de concepto único y uniforme del organismo o entidad a cargo de una función administrativa (MARIENHOFF, 2000, p. 66).

Es a partir de estas críticas que GORDILLO (1998, IX-11) considera como insuficientes los enfoques objetivo y subjetivo para determinar lo que constituye la administración pública. Con el fin de identificar esta noción, el autor promueve un criterio mixto orgánico, según el cual la función que realiza la administración no tiene un contenido único como otras funciones que realiza el Estado y, en esta medida, puede consistir tanto en la expedición de una norma jurídica de contenido general, como en una actividad prestacional, o en la decisión de casos individuales. Es a partir de un criterio mixto que se intentará identificar el sentido que tiene la expresión "administración pública" en derecho peruano.

\section{La ADMinistración Pública de Perú COMO UnA REALIDAD COMPLEJA}

Al tratar los diferentes criterios que la doctrina ha utilizado para conceptuar a la administración publica, se afirmó que es posible y necesario categorizar a la misma, pues es solo a ella a quien debe aplicarse el régimen jurídico que el ordenamiento jurídico peruano prevé para esta organización: el de derecho administrativo.

Contrario a lo que afirman los partidarios de posturas funcionalistas, consideramos que la administración pública debe ser necesariamente vista como una forma de organización del poder público que actúa en ejercicio de potestad administrativa. Al ser poder público, posee otros elementos, como son su fin público, su servicio objetivo a los intereses generales, la necesidad de satisfacer los principios de eficacia y economía, aspectos que son predicables a todos los poderes públicos. Tanto la Constitución peruana como las normas legales confieren la capacidad de ejercer potestades administrativas solo a organizaciones de carácter público. Asimismo, para identificar la naturaleza jurídica de la organización es necesario valorar la vinculación entre esta y la actividad para la que está capacitada jurídicamente: una valoración entre naturaleza (desde una perspectiva jurídico-formal) de la organización y régimen jurídico-formal de los actos. En concreto, la Constitución política de Perú establece que estas organizaciones son, indistintamente, el poder ejecutivo, algunos órganos al 
servicio del Congreso (art. $54 \mathrm{CP}$ ) o del poder judicial (art. $143 \mathrm{CP}$ ), del Tribunal Constitucional, y otras organizaciones constitucionales (arts. 20, 82, 84, 87, $150,151,158,161,176,178,182,183,191$ y 197 CP). Además, se incluirían todos los entes que legalmente son autónomos, instrumentales o no, independientes o dependientes de otras administraciones públicas (ABRUÑa y BACA, 2014, p. 12). Por tanto, los entes jurídicos-privados no son administraciones públicas, porque la forma es el primer criterio definidor o determinante de su capacidad jurídica, aunque, por excepción, y previa habilitación legal, podrán ejercer por delegación potestades administrativas, actuando entonces a ciertos efectos como administraciones públicas.

Los organismos que integran la administración pública lo hacen porque, además de ostentar la capacidad de ejercer potestades públicas, tienen unas características jurídico-formales determinadas que los diferencian. Más allá de su reconocimiento constitucional, es preciso interrogarse acerca de si el ordenamiento jurídico peruano recoge alguna norma que desarrolle un concepto único de administración pública, así como su estructura.

En derecho peruano existen una serie de disposiciones normativas cuyo enfoque varía según el objeto jurídico tutelable. A manera de ejemplo, el artículo $1 .^{\circ}$ de la Ley de Procedimiento Administrativo General, Ley n. ${ }^{\circ} 27444$, considera que son entidades de la administración pública: 1 . El poder ejecutivo, incluyendo ministerios y organismos públicos descentralizados; 2. El poder legislativo ${ }_{i} 3$. El poder judicial ${ }_{i} 4$. Los gobiernos regionales $; 5$. Los gobiernos locales; 6. Los organismos a los que la Constitución Política de Perú y las leyes confieren autonomía $;$ 7. Las demás entidades y organismos, proyectos y programas del Estado, cuyas actividades se realizan en virtud de potestades administrativas $\mathbf{y}$, por tanto, se consideran sujetas a las normas comunes de derecho público, salvo mandato expreso de ley que las refiera a otro régimen, y 8. Las personas jurídicas de derecho privado que prestan servicios públicos o ejercen función administrativa, en virtud de concesión, delegación o autorización del Estado, conforme a la normativa de la materia. Esto último, a pesar de la ausencia de reconocimiento constitucional de estos sujetos de derecho privado. Precisamente, si bien se establece una lista de las entidades que forman parte de la administración pública, cabe resaltar que nos llama la atención lo establecido en los numerales 2, 3 y 8 LPAG. Dichos numerales establecen que son entidades de la administración pública las personas jurídicas bajo el régimen privado que prestan servicios públicos o ejercen función administrativa, en virtud de concesión, delegación o autorización del Estado; el poder judicial y el poder legislativo, lo cual, se insiste, no guarda relación con la doctrina de derecho administrativo contemporánea, ni con lo establecido en la Constitución Política.

El mismo problema ocurre con la Ley n. ${ }^{\circ} 27785$, Ley Orgánica del Sistema Nacional de Control y de la Contraloría General de la República, la cual en sus literales f) y g) del artículo $3 .^{\circ}$ establece que las empresas del Estado, así 
como aquellas empresas en las que este participe en el accionariado, cualquiera sea la forma societaria que adopten, por los recursos y bienes materia de dicha participación y las entidades privadas, las entidades no gubernamentales y las entidades internacionales, exclusivamente por los recursos y bienes del Estado que perciban o administren, están sujetas a control por el sistema y se designan con el nombre genérico de entidades. Esta norma establece que están sujetos al sistema nacional de control las empresas del Estado, las entidades privadas, las entidades no gubernamentales y las entidades internacionales, exclusivamente por los recursos y bienes del Estado que perciban o administren, lo cual genera la misma contradicción señalada por la LPAG.

Por último, el Decreto Legislativo n. ${ }^{\circ}$ 1017, Ley de Contrataciones del Estado (LCE), también tiene dentro de su ámbito de aplicación su propia definición de entidades de la administración pública, las cuales abarcan las siguientes: "Se encuentran comprendidas dentro de los alcances de la presente ley, bajo el término genérico de Entidad(es): (...) i) Las empresas del Estado de derecho público o privado, ya sea de propiedad del Gobierno Nacional, Regional o Local y las empresas mixtas bajo control societario del Estado". Tal como se puede apreciar, al igual que las normas descritas, la LCE llega a la misma conclusión al considerar como entidad de la administración pública a las empresas de derecho público y privado. Esto hace que sea necesario detenernos aquí para resolver los interrogantes planteados acerca de si pueden ser administraciones públicas y actuar como tales las personas jurídicas bajo régimen público y privado. O si el poder judicial y el legislativo hacen parte de la administración pública como lo señala la LPAG y la ley de contratación estatal.

La respuesta a estos cuestionamientos debe ser negativa, ya que, como bien lo sostiene MARTIN (2011: 44), las empresas de derecho público y privado solo pueden ejercer función administrativa mediante una delegación expresa y de manera excepcional en el evento en que tengan como principal objetivo la gestión económica de un servicio. Afirma al respecto el citado autor:

"los particulares que ejercen funciones administrativas en la prestación de un servicio público por concesión, o en general, cualquier empresa, no pueden considerarse organizaciones de poder público, toda vez que son personas jurídicas de Derecho privado que actúan en nombre e interés propio y no del Estado, con la obligación de prestar servicios públicos, en virtud de un contrato de concesión celebrado con el Estado. Asimismo, estas potestades administrativas no le pertenecen ni pueden ser trasladadas del Estado al privado".

En un mismo sentido, AbruÑa (2011, p. 21) sostiene que tampoco pueden considerarse como entidades de la administración pública el poder judicial y el poder legislativo, por las siguientes razones:

"Los órganos auxiliares de los Poderes legislativo, judicial y del Tribunal Constitucional ejercen función administrativa: contratan, asumen y administran personal 
y poseen bienes; también es de reconocimiento general que toda la actividad relativa a estas materias, en última instancia, es revisada en el Poder judicial. Cuando estos poderes y el Tribunal Constitucional ejercen esas funciones es evidente que no están ejerciendo su actividad específica y lo es también que esa actividad administrativa no la ejercen los órganos legislativo, judicial o constitucional de esas organizaciones, sino otros órganos que son de apoyo a la labor específica que tienen asignada ${ }_{i}$ órganos dependientes de esas organizaciones, dirigidos por ellas, independientes de otras administraciones públicas y con las características apropiadas para ejercer poder público".

Lo aquí expuesto lleva a reconocer que en Perú existe una diversidad de normas de derecho público cuyo ámbito de aplicación se exitende a sujetos de derecho privado y a entes que no son de carácter administrativo, generando una aplicación transversal del derecho administrativo en la actualidad. Sin embargo, se hace enfásis en que existe una anomalía al señalar que dichos entes son considerados como entidades de la administración pública, ya que los mismos tienen una función distinta a la administrativa (gestión económica, legislar y juzgar).

Por el lado de la organización administrativa, hay normas de derecho público, como la Ley n. ${ }^{\circ} 29158$, Ley Orgánica del Poder Ejecutivo ${ }^{4}$; la Ley n. ${ }^{\circ}$ 27972, Ley Orgánica de Municipalidades ${ }^{5}$; la Ley n. ${ }^{\circ} 27867^{[6]}$, Ley Orgánica de Gobiernos Regionales; la Ley n. ${ }^{\circ}$ 27658, Ley Marco de Modernización de la Gestión del Estado ${ }^{7}$, entre otras, que regulan diferentes aspectos específicos

4 Artículo 1: "Objeto de la Ley. La presente Ley Orgánica establece los principios y las normas básicas de organización, competencias y funciones del Poder Ejecutivo, como parte del Gobierno Nacional ${ }_{i}$ las funciones, atribuciones y facultades legales del Presidente de la República y del Consejo de Ministros; las relaciones entre el Poder Ejecutivo y los Gobiernos Regionales y Locales; la naturaleza y requisitos de creación de Entidades Públicas y los Sistemas Administrativos que orientan la función pública, en el marco de la Constitución Política del Perú y la Ley de Bases de la Descentralización".

5 Artículo 1: "Los gobiernos locales son entidades básicas de la organización territorial del Estado y canales inmediatos de participación vecinal en los asuntos públicos, que institucionalizan y gestionan con autonomía los intereses propios de las correspondientes colectividades; siendo elementos esenciales del gobierno local, el territorio, la población y la organización".

6 Artículo 1: "Objeto y contenido de la Ley. La presente Ley Orgánica establece y norma la estructura, organización, competencias y funciones de los gobiernos regionales. Define la organización democrática, descentralizada y desconcentrada del Gobierno Regional conforme a la Constitución y a la Ley de Bases de la Descentralización".

7 Artículo 1: "Declárase al Estado peruano en proceso de modernización en sus diferentes instancias, dependencias, entidades, organizaciones y procedimientos, con la finalidad de mejorar la gestión pública y construir un Estado democrático, descentralizado y al servicio del ciudadano".

Artículo 3: "La presente Ley es de aplicación en todas las dependencias de la Administración Pública a nivel nacional". 
sobre organización de la administración pública en Perú. No obstante, profesores dedicados a esta materia, como MARTIN (2011, p. 47), afirman que no existe una norma que regule de manera uniforme y coherente la organización administrativa. Frente a esto, nos encontramos con dos difcultades: de un lado, no existe norma que desarrolle el concepto de adminsitración pública, y, de otro lado, no existe una estructura uniforme que determine los aspectos sustanciales que debe tener la estructrura de la administración pública.

Estas dificultades guardan relación con la problemática jurídica planteada en la introducción de este trabajo, en la medida en que a partir de ellas se creó el grupo de trabajo gubernamental ${ }^{8}$ que elaboró el "Proyecto de la Ley de Bases de la Administración Pública". Recordemos cómo con este proyecto se buscaba recoger todos los aspectos y fundamentos que deben enmarcar el diseño de la estructura de la administración pública peruana y solucionar, de esta manera, la falta de uniformidad en los organismos y entidades que integran la misma.

Mediante Resolución n. ${ }^{\circ}$ 0223-2014-Jus se publico en el Diario Oficial "El Peruano" el "Proyecto de la Ley de Bases de la Administración Pública". Luego de una revisión del contenido de este proyecto de ley, se procura establecer el alcance que tiene en la determinación de la noción de administración pública. El análisis realizado permite resaltar los aspectos positivos del proyecto, así como poner en evidencia aquellos puntos que debe revisar el grupo de trabajo.

\section{II. ¿HACIA LA DETERMINACIÓN DEL CONTENIDO DE LA ADMINISTRACIÓN PÚBLICA EN DERECHO PERUANO?}

Una comprensión de la administración pública como realiad compleja, a partir de la aplicación de los criterios de definición desarrollados por la doctrina en derecho administrativo, permitió, en una primera parte de este trabajo, identificar una serie de dificultades ligadas a la definición del término "administración pública" en derecho peruano. En respuesta a estas dificultades, el gobierno elaboró un proyecto de ley que busca racionalizar la compleja realidad de la estructura de la administración pública. Esta iniciativa constituye un esfuerzo de racionalización de la estructura de la administración, así como una búsqueda de mayor coherencia a través de la formulación de principios en materia de organización administrativa.

\section{UN ESFUERZO DE RACIONALIZACIÓN DE LA ESTRUCTURA DE LA ADMINISTRACIÓN PÚbliCA DE PERÚ}

Las normas del proyecto contienen una enumeración de las entidades que forman parte de la administración pública peruana, con el fin de establecer su 
ámbito de aplicación. No obstante, para entender el alcance de estas disposiciones es necesario comenzar por definir qué se entiende por "entidad pública".

Antes de la elaboración del proyecto de ley ya se había promulgado una directiva $^{9}$ en la que se había incluido un concepto único de entidad pública como "toda organización del Estado Peruano, con Personería jurídica de Derecho Público, creada por norma expresa en la que se le confieren atribuciones, mediante la administración de recursos públicos, para contribuir a la satisfacción de las necesidades y expectativas de la sociedad, y como tal está sujeta al control, fiscalización, y rendición de cuentas". Dicha definición fue novedosa en el ordenamiento jurídico peruano, al permitir identificar los elementos esenciales que debía tener cualquier organismo para ser calificado como "entidad pública". Sin embargo, dicha definición se encontraba en una norma reglamentaria, con lo cual su vigencia y estabilidad jurídica era cuestionable por existir disposiciones de rango legal que parecían alejarse de lo en ella establecido. Del mismo modo, autores como MARTIN (2011, p. 47) sostienen que la directiva en mención consagra una postura incompleta que pretende ser de aplicación a todo el universo del Estado, en función de un criterio específico, como es el de la personalidad jurídica de las entidades públicas. Esta directiva no toma precisamente en cuenta el hecho de que programas, proyectos, unidades ejecutoras y demás órganos que forman parte de estructuras administrativas no tienen personería jurídica.

En respuesta a estos inconvenientes, el proyecto de ley recoge un concepto de "entidad pública" que aparece más ajustado a la complejidad de la administración pública peruana. Así, en el proyecto se define a las entidades públicas como toda estructura organizativa del Estado con personalidad jurídica, que realiza función administrativa, se encuentra regida por normas de derecho público y cuenta con patrimonio propio para la realización de las actividades prevista en su ley de creación. De esta definición se tiene que dentro de las características de toda entidad pública se encuentra en primer lugar el hecho de que se trata de estructuras organizativas y que, como toda organización, requieren de la definición de una estructura y de unos parámetros de actuación. Asimismo, las entidaes públicas realizan función administrativa y están regidas por normas de derecho público. Además, son de creación legal y cuentan con autonomía presupuestal, administrativa y patrimonial.

La definición estudiada se muestra a priori acorde con un criterio funcional de la administración pública, de manera que podría afirmarse que los sujetos de derecho administrativo, dentro de los cuales se encuentran las entidades públicas, como centros de imputación de derechos y deberes, realizan función administrativa. Sin embargo, a pesar de que parece existir un consenso sobre

9 Directiva n. ${ }^{\circ}$ 002-2010-PCM, "Disposiciones relacionadas a la definición del concepto de entidad pública y la validación del Registro Preliminar de las entidades públicas del Estado Peruano". 
el concepto de "entidad pública", es posible cuestionarse acerca de su alcance práctico. Para esto, es necesario verificar si el proyecto de ley diferencia el concepto de entidad pública de expresiones como órgano, organismo y empresa del Estado. En cuanto a los organismos públicos, el proyecto establece que se trata de un ente adscrito a otro ente público o a un sector. Los órganos administrativos son a su vez definidos como las dependencias que integran una entidad pública u organismo púbico, al cual se le atribuye un conjunto de competencias ordenadas y orientadas a finalidades de interés general. En su composición, estos órganos pueden ser unipersonales o colegiados. Se indica además que carecen de personería jurídica. Por último, con relación a las empresas del Estado, se establece que se trata de entidades organizadas en forma societaria, en los tres niveles de gobierno, cuyo objeto es la oferta de bienes y servicios. Si bien no tienen el carácter de entidad pública, estas estructuras entran dentro del campo de aplicación del proyecto de ley, debido a que el régimen de derecho que se les aplica es el de derecho administrativo. En derecho peruano, en ningún caso las empresas del Estado tendrán personalidad jurídica, ni se les otorgarán atribuciones de imperio, salvo que la ley expresamente preveea lo contrario.

Es posible afirmar que el Proyecto de Ley de Bases de la Administración diferencia aquellos conceptos que dificultaban la construcción de una definición uniforme sobre la administración pública. Ahora bien, el hecho de que para definir organismo se recurra al término ente, esto es, a otro concepto, con el cual se busca además distinguirlo, es un punto que debe ser revisado. Tal vez sería más claro afirmar que los organismos carecen de personalidad jurídica, mientras que los entes son verdaderos centros de imputación de derechos y deberes. Ambos, organismos y entidades, estarían a su vez compuestas de órganos.

A la definición de los tipos de estructuras susceptibles de integrar la estructura de la administración, y al esfuerzo de diferenciación de las mismas, debe acompañarse una verdadera distinción entre rama ejecutiva y administración pública, siendo esta última noción más amplía: en la misma se incluyen aquellas autoridades independientes del ejecutivo que realizan función administrativa.

Del mismo modo, es conveniente que la ley de bases de la administración pública establezca aquello que se debe entender por técnicas tradicionales de organización, como son la descentralización, la desconcentración y la delegación administrativas. El proyecto en su estado actual se limita a establcer un deber de desconcentración como principio.

La presente iniciativa es por lo demás saludable en la medida en que se busca dar claridad sobre la estrcutura de la administración pública, esto es, sobre el complejo orgánico que se relaciona con el ciudadano. Se trata en últimas de ofrecer mayor garantías al administrado, al permitirle conocer la naturaleza del sujeto con el que se relaciona y el régimen de derecho que le es aplicable. La organización que da soporte al funcionamiento del Estado debe actuar en 
forma ordenada y en concordancia con una serie de principios en materia de estructura.

\section{LA BÚSQUEDA DE COHERENCIA A TRAVÉS DE PRINCIPIOS PARA LA ORGANIZACIÓN DE LA ADMINISTRACIÓN PÚBLICA}

El proyecto de ley en estudio ha recogido de manera enunciativa una lista de principios que permiten establecer con total certeza las reglas de la organización y el ejercicio de las competencias de la administración pública. Si el objetivo de estos principios es dotar al aparato administrativo de mayor coherencia, es preciso examinar aquellos que se han reconocido de manera expresa en el proyecto de ley. Asimismo, se sugieren otros principios que por su importancia y naturaleza jurídica merecen ser reconocidos de manera expresa.

El primer principio reconocido en el proyecto es el de legalidad. Este principio, entendido como una de las características determinantes del Estado de derecho y producto de la indiscutible sujeción de la administración a un orden jurídico en su sentido material (SANTOFIMIO, 2007, p. 365), se encuentra consagrado en el numeral 1, artículo II del Título preliminar del Proyecto de Ley de Bases de la Administración Pública, y establece que "la asignación, distribución y ejercicio de competencia de las entidades bajo el ámbito de aplicación de la Ley se sujetan a lo dispuesto en la Constitución Política del Perú, las leyes y el ordenamiento jurídico en general, en salvaguarda del interés público y respeto de los derechos humanos". La administración pública debe cumplir y hacer cumplir, no solo las leyes emitidas por el Congreso de la República y los gobiernos locales, sino también las normas que esta dicte, a fin de garantizar al ciudadano y demás sujetos privados o públicos que se relacionen con ella, el respeto de sus derechos y en general, al sistema jurídico. En esta misma línea, SANTAMARía PASTOR (2004, p. 80) afirma que este principio pretende resaltar el sometimiento de la administración pública a las normas emanadas por el poder legislativo $y$, en general, a las reglas que integran el sistema normativo. Por su parte, MORÓn (2011, p. 60) sostiene que dicho principio es denominado como la "vinculación positiva de la Administración a la Ley" y está referido a la necesidad de que la actuación administrativa cuente con un respaldo jurídico y constitucional. En ese sentido, debemos entender que la aplicación de dicho principio obliga a que el ejercicio organizacional y administrativo de la administración pública se encuentre conforme al ordenamiento jurídico en su conjunto.

En cuanto al principio de desconcentración, el numeral 3 del artículo II del Título Preliminar del Proyecto de la Ley de Bases de la Administración Pública establece que las entidades de la administración pública pueden desconcentrar sus competencias, creando órganos o no, sin perjuicio del deber de orientación que corresponde ejercer a los órganos de similar o superior jerarquía. En derecho peruano, la desconcentración funcional o vertical se realiza atendien- 
do al vínculo jerárquico existente entre el órgano transferente y el que ejerce las competencia, sin considerar el aspecto geográfico. La desconcentración territorial u horizontal se realiza para expandir la cobertura geográfica de los servicios administrativos de la entidad. En los términos del proyecto, la confusión entre las nociones de desconcentración y descentralización se mantiene.

Para autores como IVANEGRA (2005, p. 160), la desconcentración alude a la transferencia de las competencias de un ente central a un organismo que no constituye una persona jurídica distinta. Para ello se requiere que este ente cuente con competencias exclusivas y permanentes, que la atribución se realice hacia un órgano que no ocupe la cúspide de la línea jerárquica y en un ámbito dentro del cual el órgano debe ejercer la competencia que le fuere atribuida. Sin embargo, dicho principio debe distinguirse de la descentralización, la cual implica la transferencia de competencias decisorias de la administración estatal a las demás personas jurídico-públicas (BREWER-CARÍAS, 2005, p. 116). Es preciso diferenciar ambos conceptos: la descentralización consiste en la transferencia de la titularidad de competencias administrativas, que realiza el ordenmaniento jurídico, desde el nivel central del Estado, como sujeto de derecho público, a otro sujeto de derecho público dinstinto a él. Por el contrario, en la desconcentración el ordenamiento jurídico transfiere competencias desde un sujeto de derecho público a un organismo que se encuentra por fuera de la sede principal de ese sujeto, sin que ello implique la atribución de la personalidad jurídica, como sí ocurre en la descentralización.

Si bien la descentralización administrativa no se encuentra reconocida como principio en el proyecto de ley, es preciso resaltar que el Tribunal Constitucional peruano lo ha reconocido en diferentes sentencias, en los siguientes términos:

"Se ha precisado que un Estado 'unitario descentralizado' es meramente un Estado unitario complejo, es decir, aquel en el que la descentralización solamente se presenta en un ámbito administrativo, mas no en un ámbito político. En dichos Estados, las entidades descentralizadas no gozan de verdadera autonomía, pues, si bien tienen importantes potestades reglamentarias y ejecutivas, éstas, finalmente, reducen su cometido a la ejecución de las leyes estatales. Sin embargo, nuestra Constitución no sólo ha conferido a los gobiernos descentralizados (regional y local) autonomía administrativa, sino también económica, y, lo que es más importante, autonomía política".

De manera complementaria, SANTOFIMIO (2007, p. 411) explica que mediante el fenómeno de la descentralización el Estado se desprende de específicas funciones, asignándolas a las entidades periféricas para que estas las ejerzan autónomamente, mediante la toma de decisiones necesarias para su planteamiento y ejecución. Dentro de este contexto, el ente adquiere no solo posibilidad de administrarse, sino también de gobernarse. Si bien el principio de desconcentración ya se encuentra recogido en el proyecto de ley, cabe resaltar 
que es necesario que se reconozca también la descentralización no solo para distinguir ambas instituciones jurídicas, sino para generar uniformidad y certeza respecto de su importante aplicación por parte de la administración pública.

Otro punto que es importante considerar, sobre todo si se pretende una mejor articulación de las diferentes competencias en cabeza de los organismos y entidades que integran la administración pública peruana, es el principio de colaboración. En este sentido, el numeral 4) del artículo II del Título Preliminar del Proyecto de la Ley de Bases de la Administración Pública, en el mismo tenor, establece que "las entidades bajo el ámbito de aplicación de la ley deberán interactuar mediante relaciones de coordinación y cooperación en forma permanente y continua, sin interferir las competencias que posea cada una de ellas. Las relaciones entre entidades tendrán como objetivo mantener una orientación institucional coherente, que garantice la complementariedad de sus competencias institucionales". Este principio busca dotar de armonía y equilibrio a la actuación de la administración pública, adoptando acciones que busquen la coherencia y la actuación sincronizada o jerarquizada. Sin embargo, cabe resaltar que dicho artículo no solo recoge a la colaboración como principio, sino además a la colaboración, con lo cual nos encontramos frente a dos principios distintos y con finalidades diferentes. La diferencia entre el principio de coordinación y el de colaboración radica en que la coordinación es un principio que se aplica entre dos o más entidades de diferente rango jerárquico, mientras la colaboración se da entre dos o más entidades de la misma jerarquía. Por lo tanto, resulta pertinente realizar dicha diferenciación en el marco del proyecto de la ley con miras a generar predictibilidad y uniformidad en el marco de la organización administrativa de la administración pública (PAREJO, 2010, p. 185).

Respecto del principio de asignación de competencias, el proyecto de ley establece en el numeral 5 del artículo II del Título Preliminar que "la asignación de competencia de las entidades u organismos públicos se realiza mediante la distribución clara y precisa de estas, comprendiendo la facultad de actuar y la obligación de ejercerla bajo las condiciones, límites y procedimientos establecidos en el orden jurídico". Sobre el particular, LinARES (1986, p. 228) expone que la competencia es uno de los principios que es erigido para preservar y proteger el cumplimiento de las finalidades públicas o de bien común que la administración persigue. En esa condición puede ser analizada como principio jurídico fundamental de toda organización pública del Estado. En esa misma línea, IVANEGRA (2005, p. 136) sostiene que este principio se define como el conjunto de funciones que un agente legítimamente puede ejercer. Implica la medida de las actividades que la conforman y su aptitud legal de obrar. Asimismo, señala que la competencia representa para el órgano u organismo que la ejerza una autorización y una limitación a la vez, dado que es una suerte de autorización para el cumplimiento de la función asignada y una limitación para el cumplimiento de dicha función. Cabe resaltar que cierto sector de la 
doctrina sostiene que el ejercicio correcto de la competencia dependerá de si las potestades son regladas o discrecionales. Frente a ello nos preguntamos: ¿es cierto lo descrito? Para dar respuesta a lo mencionado, por potestad reglada (PAREJO AlFONSO, 1998, p. 370) se refiere a la acción administrativa como aquella que está prefigurada estrictamente y se circunscribe a la ejecución de la norma, mientras que por potestad discrecional (COMADIRA JuLIO, 2003, p. 428) establece estar en un espacio libre sujeto a las valoraciones funcionales, pero sin transgredir el ordenamiento jurídico. En tal sentido, independientemente de las funciones asignadas, lo relevante es que la administración pública debe ejercer sus competencias siempre dentro del marco del ordenamiento jurídico (De Esteban y García-TrevijanO, 1992, p. 97). Resulta importante destacar el reconocimiento de este principio en el proyecto de ley debido a que la competencia es uno de los factores determinantes que permite a las entidades de la administración pública establecer hasta dónde llegan sus funciones y objetivos dentro del marco de la ley y la Constitución.

Según Santamaría PASTOR (2004, p. 79), el principio jurisdiccional es consecuencia del principio de legalidad, dado que el obedecimiento al sistema jurídico requiere la existencia de un conjunto de mecanismos de control mediante los cuales se puede asegurar eficazmente el sometimiento de la administración al sistema normativo. De acuerdo a este principio, MARTIN (2011, p. 46) afirma que en el ordenamiento jurídico peruano existen mecanismos de control de la actuación de la administración pública, como el proceso contencioso administrativo y procesos constitucionales. Por lo tanto, es necesario reconocer dicho principio en el proyecto de ley como garantía fundamental, debido a que ello permitiría que las funciones y actos de las entidades de la administración se encuentren sometidos al poder jurisdiccional en caso de incumplimiento o incorrecto ejercicio.

\section{CONSIDERACIONES FINALES}

En la actualidad, el concepto de administración pública está aún lejos de ser pacífico en derecho administrativo peruano y en la doctrina nacional y extranjera examinada. Sin embargo, el Proyecto de la Ley de Bases de la Administración Pública ha dado un primer paso al definir, desde un punto de vista orgánico, las diferentes estructuras que integran la administración pública, para diferenciarlas entre sí. Ahora bien, estas definiciones carecen de claridad suficiente, punto que debe ser revisado por los autores del proyecto. Una distinción entre organismos y entidades basada en la técnica de la atribución de la personalidad jurídica debe considerarse. Adicionalmente, a la definición de los tipos de estructuras susceptibles de integrar la estructura de la administración y el esfuerzo de diferenciación de las mismas debe acompañarse una verdadera distinción entre rama ejecutiva y administración pública, siendo esta última noción más amplia, 
e incluyendo en la misma aquellas autoridades independientes del ejecutivo que realizan función administrativa. Por último, es conveniente que la ley de bases de la administración pública establezca aquello que se debe entender por técnicas tradicionales de organización, como son la descentralización, la desconcentración y la delegación administrativas. El proyecto en su estado actual se limita a establcer un deber de desconcentración como principio. No debe olvidarse que los principios que rigen la organización administrativa de la administración pública deben tener un enfoque más práctico y formal en su redacción, separando conceptos como "desconcentración" y "descentralización" e incorporando principios como "el jurisdiccional", a pesar de que la lista del proyecto de ley solo tenga un carácter enunciativo.

\section{BIBLIOGRAFÍA}

Abruña Puyol, Antonio (2011). El Concepto de Administración Pública, en La Ley de Procedimiento Administrativo General. Diez años después. Lima: Palestra.

Abruña Puyol, Antonio y Baca, Víctor (2014). Notas al Curso de Derecho Administrativo. Lima: Universidad de Piura.

Brewer-Carías, Allan R. (2005). Derecho administrativo, t. II. Bogotá: Universidad Externado de Colombia.

Comadira, Julio (2003). Derecho Administrativo. Buenos Aires: LexisNexis.

De Esteban, Jorge y Gonzales-Trevijano, Pedro (1992). Curso de Derecho Constitucional Español. Madrid: UCM.

FORSTHOFF, ERnST (1958). Tratado de Derecho Administrativo. Madrid: Instituto de Estudios Políticos y Constitucionales.

García de Enterría, Eduardo y Ramón Fernandez, Tomás (2002). Curso de Derecho Administrativo, t. I, 8. ${ }^{\text {a }}$ ed. Madrid: Civitas.

Garrido Falla, Fernando (1994). Tratado de Derecho Administrativo, t. I, 12. ${ }^{\text {a }}$ ed. Madrid: IEP.

Gordillo, Agustín (1998). Tratado de Derecho Administrativo. Parte General. 4. a ed. Buenos Aires: Fundación de Derecho Administrativo.

Mabel Ivanegra, Miriam (2005). Principios de la Administración Pública. 6. a ed. Buenos Aires: Abaco de Rodolfo de Palma. 
Marienhoff, Miguel (2000). Tratado de Derecho Administrativo. Parte General. 5. a ed. Buenos Aires: Abeledo-Perrot.

Martin Tirado, Richard (2011). Administración Pública y Procedimiento Administrativo General. Razones para su vinculación, en La Ley de Procedimiento Administrativo General. Diez años después. Lima: Palestra.

Moron Urbina, Juan Carlos (2011). Comentarios a la Ley de Procedimiento Administrativo

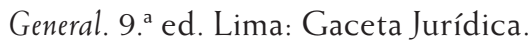

LinARES, JuAn (1986). Derecho Administrativo. Buenos Aires: Astrea.

Parejo Alfonso, Luciano (2010). Lecciones de Derecho administrativo. 3. a ed. Bogotá: Universidad Externado de Colombia.

Parejo Alfonso, Luciano (1998). La actividad de la Administración Pública: sus características, clasificación y formas, en Manual de Derecho Administrativo. Barcelona: Ariel.

Santofimio Gamboa, Jaime Orlando (2007). Tratado de Derecho Administrativo, t. I, 3. ed. Bogotá: Universidad Externado de Colombia.

Santamaría Pastor, Juan Alonso (2004). Principios de Derecho Administrativo General. Madrid: Iustel. 